Article

\title{
Fast Method for Testing the Photocatalytic Performance of Modified Gypsum
}

\author{
Magdalena Janus ${ }^{1,2, * \mathbb{D}}$, Kamila Zając ${ }^{1}$, Clemens Ehm ${ }^{2}$ and Dietmar Stephan ${ }^{2}$ (D) \\ 1 Department of Sanitary Engineering, West Pomeranian University of Technology, Szczecin, al. Piastów 50, \\ 70-311 Szczecin, Poland \\ 2 Building Materials and Construction Chemistry, Technische Universität Berlin, Gustav-Meyer-Allee 25, \\ 13355 Berlin, Germany \\ * Correspondence: mjanus@zut.edu.pl; Tel.: +48-91-449-4083
}

Received: 31 July 2019; Accepted: 13 August 2019; Published: 15 August 2019

\begin{abstract}
The measurement of the photocatalytic activity of building materials is quite time-consuming. Up until now, researchers have mainly used the equipment described in ISO 22197-1 to ISO 22197-4 for the determination of air purification activity, although other apparatus such as colorimeters, UV-Vis/DR spectroscopes and equipment for contact angle measurements have also been used. Usually, photocatalytic activity measurements take from one hour up to several hours. In this study, we present a very fast method for the measurement of the photocatalytic activity of gypsum. A specially designed printer with a modified bubblejet cartridge was used to apply a special ink on the surface of gypsum plates. Then the surface was irradiated by UV-A light and every $3 \mathrm{~s}$ a picture of the surface was taken. The results showed that the discoloration of the dye occurs after a few seconds of irradiation and the time depends on the amount of photocatalyst used as well as the number of printed ink layers. It was concluded that it is possible to use this method for a quick comparison of the photocatalytic activity of different types of modified gypsum materials.
\end{abstract}

Keywords: photoactive gypsum; photoactivity measurements; titanium dioxide

\section{Introduction}

Photoactive building materials have become more popular not only among researchers as research objects, but also in real-life applications as materials for air purification. It is possible to find buildings, glass, walls, and sidewalks covered by photoactive surfaces. Such building materials, which can be used for air purification, can also have self-cleaning and antibacterial properties.

Photocatalysis is a catalysis process that is used to provide sustainable solutions in several different fields such as biorefinery [1], organocatalysis [2], waste valorization [3], hydrogen evolution [4] and water purification [5].

Photocatalysis is also an advanced oxidation process, indeed, the activity of photoactive building materials is based on this process. For many years, photocatalysis has been known mainly for its use in water purification. More recently, it was discovered that photocatalysts may also be used as additives in building materials.

Following the production of photoactive building materials, it is always necessary to measure its photocatalytic activity. Different methods for measuring photocatalytic activity are used depending on the kind of building materials. These methods are mainly based on dyes and NOx decomposition. The typical test method to evaluate the photocatalytic air-purifying capability is to perform the measurements as described in the ISO 22197-1 to ISO 22197-4 and related international standards [6-10]. The selection of the proper method for photocatalytic activity measurements strongly depends on the type of tested building materials. In their review article, Da Silva et al. [11] described 
methods for measuring the photocatalytic activity of ceramic tiles. They suggested that in the case of ceramic tiles, the measurement of dye degradation is the most frequently used method.. However, sometimes water contact angle and NOx degradation measurements are also used. The photocatalytic activity of cementitious materials is mainly measured by nitrogen oxide decomposition [12] and dye decomposition $[13,14]$.

Usually, the following methods are applied to incorporate $\mathrm{TiO}_{2}$ photocatalysts into cementitious materials: (1) the addition of $\mathrm{TiO}_{2}$ particles during mixing of the cementitious material; (2) direct painting of the cementitious matrix surface using $\mathrm{TiO}_{2}$ suspension; and (3) sprinkling of $\mathrm{TiO}_{2}$ photocatalyst onto fresh cementitious materials surface. Binas et al. [12] prepared photoactive materials by the addition of modified $\mathrm{TiO}_{2}(5$ and $10 \% w / w)$ into the cement. The laboratory-made photocatalytic cement-based coatings were mixed with $\mathrm{Mn}$-doped $\mathrm{TiO}_{2}$ and then deposited on three different substrates (glass, plywood and gypsum). They examined the ability/efficiency of the samples based on the photocatalytic removal of NO from an air environment. Luévano-Hipólito et al. [15] measured the photocatalytic self-cleaning efficiency of coatings according to the ISO 10678:2010 norm by using aqueous methylene blue (MB) as a model pollutant in order to measure the photoactive surface's ability to degrade dissolved organic molecules under light irradiation.

There is not a lot of work on the photocatalytic activity of gypsum materials. One paper by Krutsko et al. [16] reported the testing of the photocatalytic activity of gypsum by decomposition of model contaminate (Rhodamine C) under UV. Also, one of our earlier works about photocatalytic measurements of gypsum activity. describes the NOx decomposition under UV light irradiation [17]. Another work reports the evaluation of the photocatalytic activity of gypsum materials using model dyes: mono azo dye (Reactive Red 198) decomposition under $15 \mathrm{~h}$ of UV and Vis light irradiation [18] and Reactive Orange decomposition under $40 \mathrm{~h}$ of UV light irradiation [19]. To measure photocatalytic activity during NOx degradation, $30 \mathrm{~min}$ of studies is necessary while dye decomposition requires $15-40 \mathrm{~h}$.

In this paper, a fast method for measuring photocatalytic gypsum materials activity is presented. A period of $<5 \mathrm{~min}$ is enough to determine the differences between the photocatalytic activities of different materials.

\section{Results and Discussion}

The surface of gypsum plates containing 1,3 and $5 \mathrm{wt} . \%$ of $\mathrm{TiO}_{2} / \mathrm{N}$ was covered by two layers of ink. Thereafter, there were no difference between the gypsum plates' surfaces. Namely, all samples had the same blue color. Directly after printing, each sample was irradiated by UV-A light, and changes in the color were monitored by taking pictures regularly. In Table 1, the images of the surface of unmodified gypsum and gypsum plates modified by the addition of different amounts of nitrogen modified titanium dioxide are presented. All measurements took only $132 \mathrm{~s}$, which was enough time to ascertain the differences between the materials. It is easy to observe that in the case of pure gypsum, there were no color changes, and the surface remained blue during the measurement period. It is also possible to see that with the increase the photocatalyst added into the gypsum matrix, the discoloration of the surfaces was more rapid and the blue color changed into the pink. The fastest discoloration occurred on the surface with the addition of $5 \mathrm{wt} . \%$ of $\mathrm{TiO}_{2} / \mathrm{N}$. The light pink color appeared on the photocatalytic sample (gypsum $+5 \% \mathrm{TiO}_{2} / \mathrm{N}$ ) after $24 \mathrm{~s}$ of UV-A irradiation.

Using the operating program, the function that presents the color changes of the surfaces of the unmodified and modified gypsum plates was specified. The course of the color variations is presented in Figure 1. The function confirmed the observations carried out by the naked eye. In the case of pure gypsum, there was nearly no change in color value. The color of the surface was blue during the $300 \mathrm{~s}$ of irradiation, which correlated with a linear function. In contrast to pure gypsum, the modified gypsum plates showed a completely different course. Firstly, the changes in color value were more significant with an increasing dose of photocatalyst in the gypsum plates. The fastest removal of dye was achieved for gypsum with $5 \mathrm{wt} . \%$ of $\mathrm{TiO}_{2} / \mathrm{N}$ and the slowest was for gypsum with $1 \mathrm{wt} . \%$ 
of $\mathrm{TiO}_{2} / \mathrm{N}$. Secondly, the fastest degradation of dye was during the first minute of irradiation for all three modified samples. In the next seconds of irradiation, the color changes were not so evident. This corresponds well with observations made by many authors [20] in relation to the mechanisms of photocatalysis. Namely, when the photocatalysis time is prolonged, the intermediate products that are created compete for oxidative species with the main pollutant, which resulted in slower degradation of the main compound in the dye molecules in this study. It ought to be stressed that in our case, the observation was carried out in a very short period of time.

Table 1. The photos of gypsum plates (pure gypsum and gypsum modified by addition of $1 ; 3$ and $5 \mathrm{wt} . \%$ of $\mathrm{TiO}_{2} / \mathrm{N}$ ) covered with two layers of dye during the photocatalytic process (UV-A irradiation for $132 \mathrm{~s})$.

\begin{tabular}{|c|c|c|c|c|}
\hline Time [s] & Gypsum & Gypsum $+1 \% \mathrm{TiO}_{2} / \mathrm{N}$ & Gypsum $+3 \% \mathrm{TiO}_{2} / \mathrm{N}$ & Gypsum $+5 \% \mathrm{TiO}_{2} / \mathrm{N}$ \\
\hline 0 & & & & \\
\hline 12 & & & & \\
\hline 24 & & & & \\
\hline 36 & & & & \\
\hline 48 & & & & \\
\hline 60 & & & & \\
\hline 72 & & & & \\
\hline 84 & & & & \\
\hline 96 & & & & \\
\hline 108 & & & & \\
\hline 120 & & & & \\
\hline 132 & & & & \\
\hline
\end{tabular}

The proposed fast method for photocatalytic activity measurements allowed us to examine how fast the dye could be removed from the surface of gypsum plates depending on the number of dye layers on the surface. In Table 2, the discoloration time for samples with different numbers of dye layers is presented. It can be seen that one layer of dye was removed from the gypsum plaster surface after $30 \mathrm{~s}$, but with the increase of the number of layers, the discoloration time also increased. In the experiment where the application of eight layers of dye on the gypsum surface was applied, $174 \mathrm{~s}$ was needed to decompose the dye. 


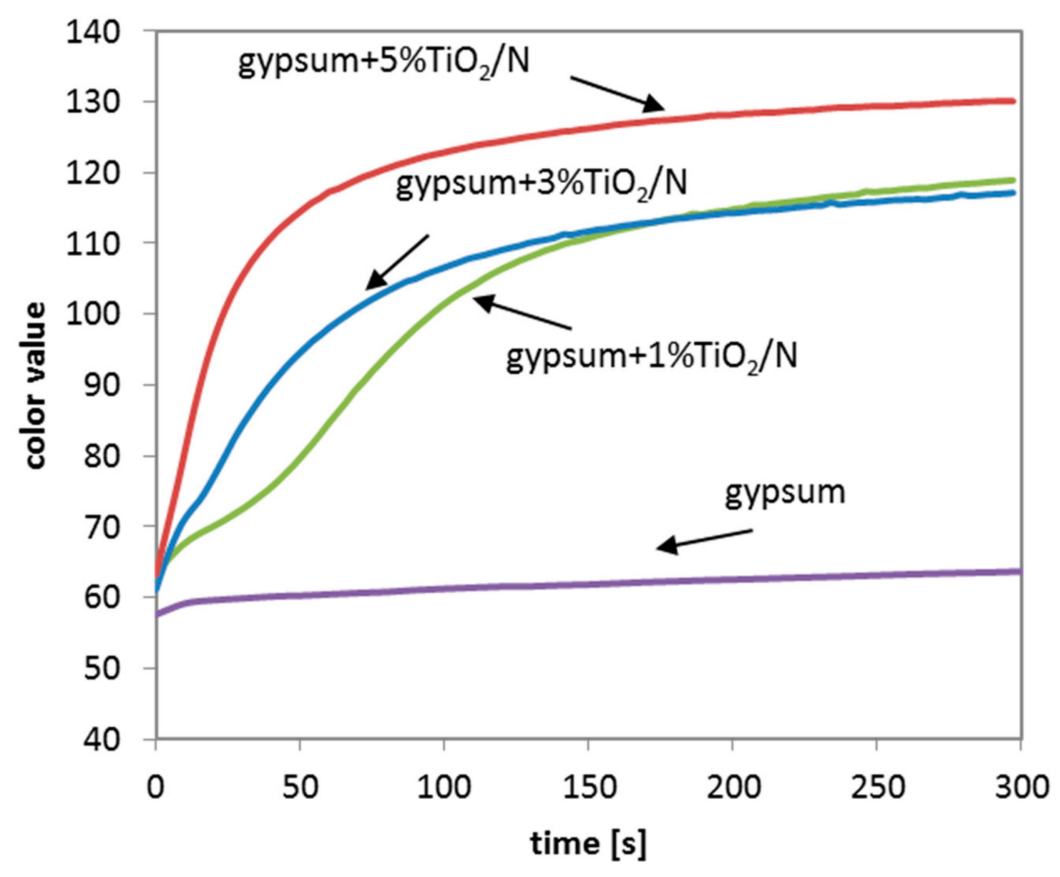

Figure 1. The changes in the color value for unmodified gypsum and gypsum modified by the addition of 1,3 and 5 wt. $\%$ of $\mathrm{TiO}_{2} / \mathrm{N}$ during the $300 \mathrm{~s}$ of UV-A irradiation.

Table 2. Discoloration time of gypsum with the addition of $1 \mathrm{wt} . \% \mathrm{TiO}_{2} / \mathrm{N}$ according to the number of ink layers.

\begin{tabular}{cc}
\hline Numbers of Layers & Discoloration Time (s) \\
\hline 1 & 30 \\
2 & 69 \\
3 & 93 \\
4 & 102 \\
5 & 120 \\
6 & 135 \\
7 & 139 \\
8 & 174 \\
\hline
\end{tabular}

By using this method, it was also possible to control the lifetime of modified gypsum plates. After the discoloration, the surface of modified gypsum plates was covered again with dye; this process was repeated five times. The discoloration time after each cycle is presented in Table 3. It appeared that the time of discoloration increased as the number of cycles increased.

Table 3. The lifetime of gypsum modified by addition of $1 \mathrm{wt} . \%$ of $\mathrm{TiO}_{2} / \mathrm{N}$ control by measuring the discoloration time. In the first cycle, the surface of gypsum was covered by two layers of dye and after discoloration, two layers new were print on gypsum surface., this process was repeated 5 times.

\begin{tabular}{cc}
\hline Cycle Number & Discoloration Time (s) \\
\hline 1 & 87 \\
2 & 96 \\
3 & 111 \\
4 & 126 \\
5 & 144 \\
\hline
\end{tabular}

Additionally, a comparison between the results obtained during the dye discoloration and the NOx decomposition on modified gypsum materials was done. As can be observed in Figure 2, 
the comparison led to an interesting analogy. In the case of gypsum modified by the addition of $1 \mathrm{wt} . \%$ $\mathrm{TiO}_{2} / \mathrm{N}$, the NOx removal amounted to $32 \%$ and dye discoloration occurred after $114 \mathrm{~s}$. This is the lowest NOx removal and the longest discoloration time for all of the tested gypsum materials. As was expected, the highest activity occurred in gypsum modified by the addition of $5 \mathrm{wt} . \% \mathrm{TiO}_{2} / \mathrm{N}$. In this sample, the NOx removal amounted to $57 \%$ and the corresponding dye discoloration took place after $36 \mathrm{~s}$. Summarizing, these studies showed that the proposed method of photocatalytic determination of the photocatalytic properties of gypsum materials based on dye discoloration is comparable to NOx decomposition data. However, the main advantage of the new method is the time factor (very fast analyses) and the relative simplicity of the measurement procedures.

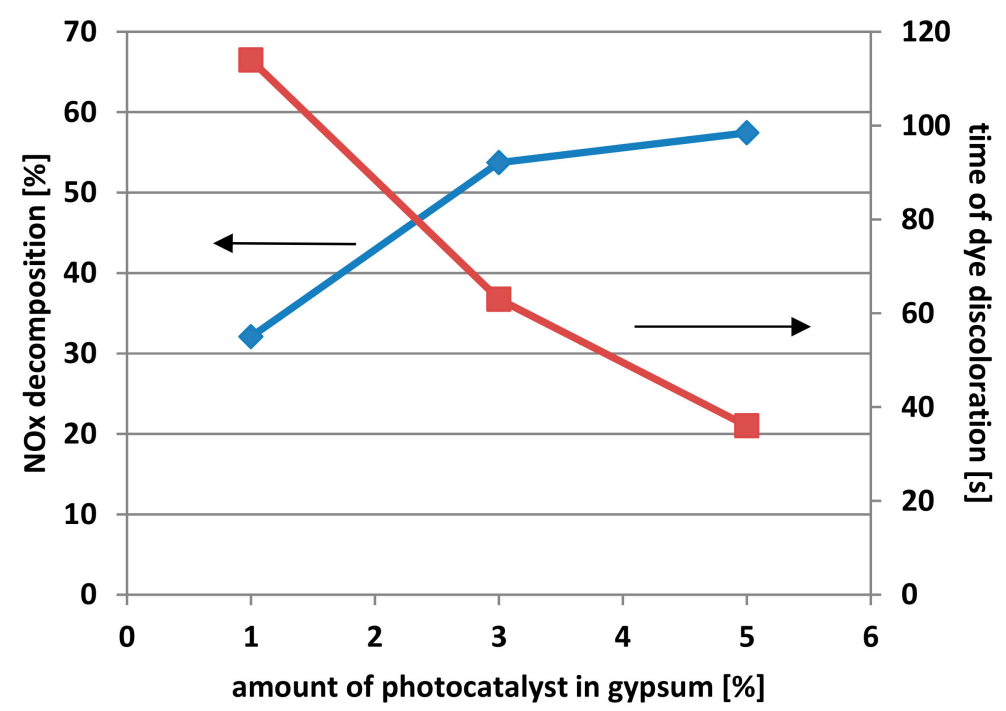

Figure 2. NOx decomposition [\%] and dye discoloration time [s] on modified gypsum materials. Modification was conducted by the addition of $1 ; 3$ and 5 wt. $\%$ of $\mathrm{TiO}_{2} / \mathrm{N}$ to the gypsum matrix.

\section{Materials and Methods}

\subsection{Materials}

Commercial gypsum (Dolina Nidy Sp. z o.o., Poland) was used for the preparation of the modified gypsum plates. The beginning of the setting time amounted to $3 \mathrm{~min}$. The BET surface area of fixed gypsum was $23 \mathrm{~m}^{2} \mathrm{~g}^{-1}$, and the average gypsum micro-particle size was $12.45 \mu \mathrm{m}$.

The preparation of the photocatalyst $\left(\mathrm{TiO}_{2} / \mathrm{N}\right)$ was carried out using the HEL Ltd. Autolab E746 installation. The commercial titanium dioxide supplied by Grupa Azoty Zakłady Chemiczne 'Police' S.A. (Poland) was used as a starting material. $\mathrm{TiO}_{2}(600 \mathrm{~g})$ and $350 \mathrm{~mL}$ of $\mathrm{NH}_{4} \mathrm{OH}$ were placed in a temperature-pressure reactor. The reactor was closed and the mixture was blended using a magnetic stirrer and heated up to $100^{\circ} \mathrm{C}$ for $4 \mathrm{~h}$. Afterwards, the catalyst was dried in air for $4 \mathrm{~h}$ at $100{ }^{\circ} \mathrm{C}$. Finally, the obtained photocatalyst $\mathrm{TiO}_{2} / \mathrm{N}$ was ground with a mortar to form a fine powder. The physico-chemical characteristics of $\mathrm{TiO}_{2} / \mathrm{N}$ are presented in Table 4.

Table 4. Physico-chemical properties of $\mathrm{TiO}_{2} / \mathrm{N}$ which was added to gypsum in $1 ; 3$ and 5 wt.\% [21].

\begin{tabular}{|c|c|c|c|c|c|c|}
\hline \multicolumn{3}{|c|}{ Phase Participation (\%) } & \multirow{2}{*}{$\begin{array}{l}\text { Crystal Size of } \\
\text { Anatase (nm) }\end{array}$} & \multirow{2}{*}{ SBET $\left(m^{2} g^{-1}\right)$} & \multirow{2}{*}{ EG (eV) } & \multirow{2}{*}{$\begin{array}{l}\text { Izoelectric } \\
\text { Point } \mathrm{pH}_{\mathrm{pzc}}\end{array}$} \\
\hline Anatase & Rutile & Amorphous & & & & \\
\hline 31.9 & 3.0 & 65.1 & 10.8 & 235 & 3.2 & 5.83 \\
\hline
\end{tabular}

The gypsum plates were prepared by mixing different amounts of $\mathrm{TiO}_{2} / \mathrm{N}$ photocatalyst (in the range of 1-5wt.\%) with pure gypsum. The powders were blended with distilled water (water-to-gypsum ratio $\mathrm{w} / \mathrm{g}=0.6$ for pure gypsum). The addition of photocatalyst to gypsum matrix led to a significant 
increase in gypsum paste density, which resulted in a decrease in workability. Therefore, with the increase in photocatalyst loading, a higher water-to-gypsum ratio was applied, $\mathrm{w} / \mathrm{g}=0.61 ; \mathrm{w} / \mathrm{g}=$ 0.65 and $\mathrm{w} / \mathrm{g}=0.69$ for $1 \mathrm{wt} . \% ; 3 \mathrm{wt} . \%$ and $5 \mathrm{wt} . \%$ of $\mathrm{TiO}_{2} / \mathrm{N}$, respectively. The obtained plates were poured into silicone moulds $\left(80 \times 45 \times 12 \mathrm{~mm}^{3}\right)$ and set aside for solidification of the materials. Then, the six gypsum plates were removed from moulds and dried in the air to obtain dry matter. In Figure 3 , the SEM image of gypsum with $5 \%$ of $\mathrm{TiO}_{2} / \mathrm{N}$ is presented.

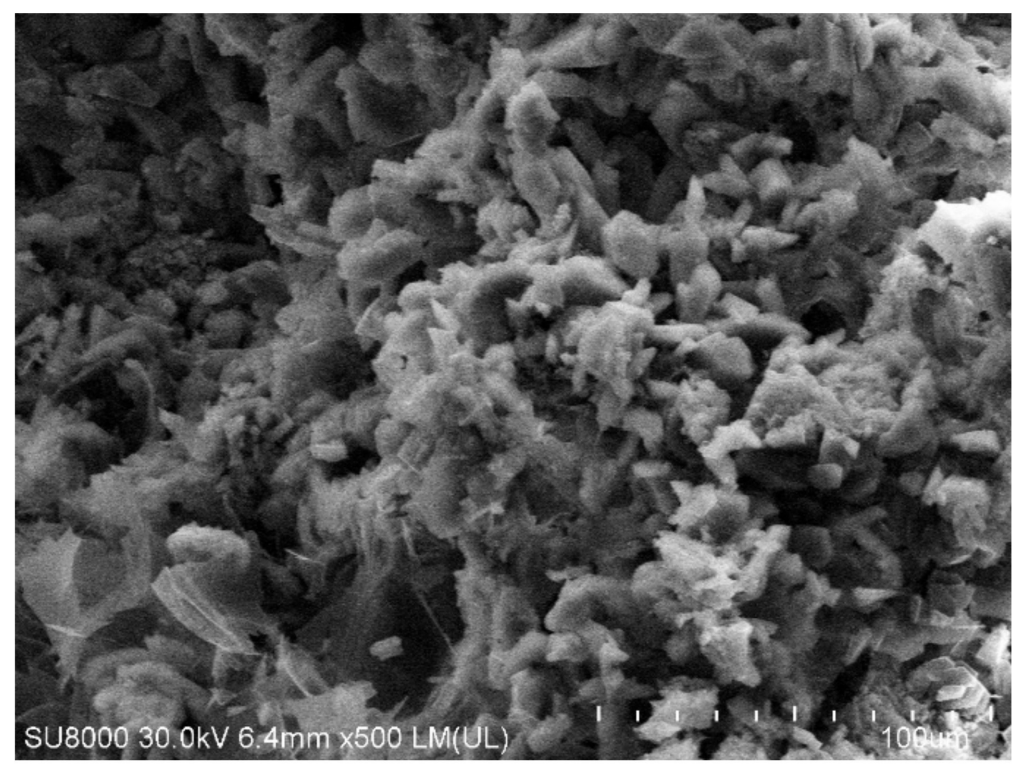

Figure 3. The SEM micrograph of gypsum with the addition of $5 \mathrm{wt} . \%$ of $\mathrm{TiO}_{2} / \mathrm{N}$.

\subsection{Photocatalytic Activity Tests}

\subsubsection{Dye Decomposition}

The following procedure was used for ink preparation, chemicals were mixed for $20 \mathrm{~min}: 0.25 \mathrm{wt} . \%$ of Resazurin Salt, $5 \mathrm{wt}$ \% of 2-Pyrrolidone, $0.2 \mathrm{wt}$ \% of Polysorbate, $20 \mathrm{wt} . \%$ of Glycerol, $8 \mathrm{wt} . \%$ of Diethylenglycol, and $66.5 \mathrm{wt} . \%$ of deionized Water. The theoretical ink layer height was $1.6 \mu \mathrm{m}$. A 2D CNC movement system with an $\mathrm{x}$ and $\mathrm{y}$-stepping resolution of $50 \mathrm{~mm}$, described fully by Ehm and Stephan [22], was used for printing. The printhead we used, a HP C6602A is capable of a printing resolution of $96 \mathrm{dpi}$ that equals $250 \mathrm{~mm}$ between the printing nozzles. The distance between the printhead and the surface of the sample was $10 \mathrm{~mm}$. The source of light was 28 UVEDs Type Nichia NSSU100CT with a peak wavelength of $365 \mathrm{~nm}$ and a spectrum half width of $12 \mathrm{~nm}$, which provides an even distributed UV-A irradiation of $(1.5 \pm 0.3) \mathrm{mWcm}^{-2}$. The surface of the gypsum plates was irradiated by UV-A light and every $3 \mathrm{~s}$, the UV-A light was switched off and a picture was taken. All tests were repeated 3 times.

\subsubsection{NOx Decomposition}

The effect of the photocatalytic activity of prepared gypsum plates on the degradation of air pollution was also proved. In our previous work [21], the NO gas (1.989 ppm $\pm 0.040 \mathrm{ppm}$, Air Liquid) was used to model pollution in photocatalytic tests. NOx removal was evaluated using the experimental installation, and the scheme is presented in Figure 4.

The gypsum plates (four at dimensions of $20 \times 20 \times 4 \mathrm{~mm}^{3}$ ) were placed in the central part of a cylindrical reactor (Pyrex glass; $\varnothing \times \mathrm{H}=9 \times 32 \mathrm{~cm}^{2}$ ) and the reactor was tightly closed. The NO was diluted with humidified synthetic air in the ratio 1:1. The oxygen and water molecules were necessary for the formation of oxidative species, which are essential in photocatalytic reactions. The polluted air flowed through the reactor continuously at a rate of $500 \mathrm{~cm}^{3} \mathrm{~min}^{-1}$. At the beginning of the 
process, the dark conditions were maintained until NO concentration reached equilibrium (about 1 ppm during about $35 \mathrm{~min}$ ). Then the UV lamps were turned on for $30 \mathrm{~min}$. The irradiation sources surrounded the reactor and were characterized by the cumulative intensity of $100 \mathrm{Wm}^{-2} \mathrm{UV}$ and $4 \mathrm{Wm}^{-2}$ vis. The temperature of the whole system was maintained at $22^{\circ} \mathrm{C}$ by using a thermostatic chamber. The $\mathrm{NO}$ and $\mathrm{NO}_{2}$ concentrations were continuously measured in the outlet of the reactor using a chemiluminescent NOx analyzer (T200, Teledyne).

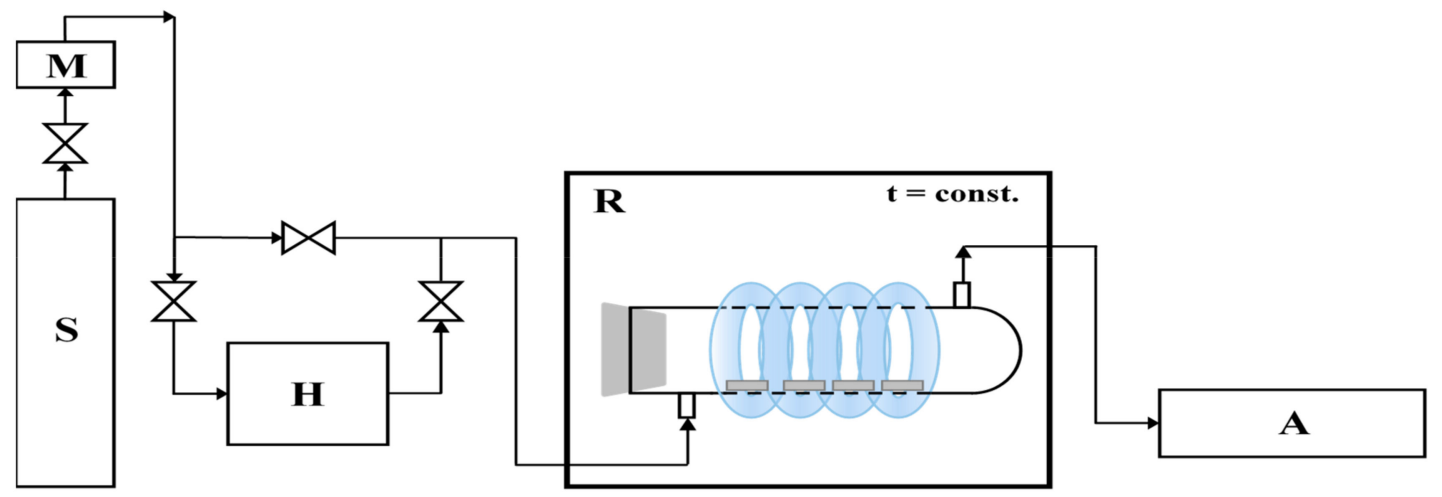

Figure 4. The scheme of installation for photocatalytic removal of NOx (S-source of pollution; $\mathrm{M}$-mass flower; $\mathrm{H}$-humidifier; $\mathrm{R}$ - photocatalytic reactor with irradiation source; A-NOx analyzer.

\section{Conclusions}

These studies showed that the equipment designed and built by Ehm and Stephan [22] may be used for measuring the photocatalytic activity of photoactive gypsum materials and it is possible to cut the measurement time to $5 \mathrm{~min}$. Measuring the photocatalytic activity of the same type of samples during NOx decomposition requires at least one hour of measurements, and dye decomposition measured by using colorimetry or UV-Vis/DR spectroscopy need several hours of irradiation. It is also possible to enlarge the scale and measure the bigger objects and to measuring the photocatalytic activity of different types of building materials.

Author Contributions: Conceptualization, M.J.; methodology, M.J. and C.E.; investigation, M.J. and K.Z.; data curation, M.J. and C.E.; writing—original draft preparation, M.J. and K.Z.; writing—review and editing, M.J. and D.S.; visualization, M.J. and K.Z.; funding acquisition, M.J.

Funding: This research was funded by the Polish National Agency for Academic Exchange within the Bekker programme.

Conflicts of Interest: The authors declare no conflict of interest.

\section{References}

1. Zhang, C.; Jia, C.; Cao, Y.; Yao, Y.; Xie, S.; Zhang, S.; Lin, H. Water-assisted selective hydrodeoxygenation of phenol to benzene over the Ru composite catalyst in the biphasic process. Green Chem. 2019, 21, 1668-1679. [CrossRef]

2. Didaskalou, C.; Kupai, J.; Cseri, L.; Barabas, J.; Vass, E.; Holtzl, T.; Szekely, G. Membrane-Grafted Asymmetric Organocatalyst for an Integrated Synthesis-Separation Platform. ACS Catal. 2018, 8, 7430-7438. [CrossRef]

3. Wilson, A.N.; Dutta, A.; Black, B.A.; Mukarakate, C.; Magrini, K.; Schaidle, J.A.; Michener, W.E.; Becham, G.T.; Nimlos, M.R. Valorization of aqueous waste streams from thermochemical biorefineries. Green Chem. 2019, 21, 4217-4230. [CrossRef]

4. Sun, C.; Zeng, J.; Lei, H.; Yang, W.; Zhang, Q. Direct Electrodeposition of Phosphorus-Doped Nickel Superstructures from Choline Chloride-Ethylene Glycol Deep Eutectic Solvent for Enhanced Hydrogen Evolution Catalysis. ACS Sustain. Chem. Eng. 2019, 7, 1529-1537. [CrossRef]

5. Wang, M.; Li, X.; Zhang, T.; Deng, L.; Li, P.; Wang, X.; Hsiao, B.S. Eco-friendly poly(acrylic acid)-sodium alginate nanofibrous hydrogel: A multifunctional platform for superior removal of $\mathrm{Cu}(\mathrm{II})$ and sustainable catalytic applications A Physicochemical and engineering aspects. Colloid Surf. 2018, 558, 228-241. [CrossRef] 
6. DIN German Institute for Standardization. Fine Ceramics (Advanced Ceramics, Advanced Technical Ceramics)_Test Method for Air-Purification Performance of Semiconducting Photocatalytic Materials_Part 1: Removal of Nitric Oxide; Beuth Verlag GmbH: Berlin Germany, 2007.

7. Italian Standards, Determination of The Degradation of Nitrogen Oxides in the Air by Inorganic Photocatalytic Materials: Continuous Flow Test Method 91.100.01. 2010. Available online: https:/infostore.saiglobal.com/ en-gb/Standards/UNI-11247-2007-677718/ (accessed on 18 April 2019).

8. German Institute for Standardization. Photocatalytic Activity of Surfaces-Determination of the Photocatalytic Deposition Velocity of Nitrogen Monoxide at Photocatalytically Active Surfaces; Beuth Verlag GmbH: Berlin, Germany, 2016.

9. DIN German Institute for Standardization. Photocatalysis—Continuous Flow Test Methods_Part 1: Determination of the Degradation of Nitric Oxide (NO) in the Air by Photocatalytic Materials; Beuth Verlag GmbH: Berlin, Germany, 2017.

10. Amrhein, K.; Stephan, D. Principles and test methods for the determination of the activity of photocatalytic materials and their application to modified building materials. Photochem. Photobiol. Sci. 2011, 10, 338-342. [CrossRef] [PubMed]

11. Da Silva, A.L.; Dondi, M.; Raimondo, M.; Hotza, D. Photocatalytic ceramic tiles: Challenges and technological solutions. J. Europ. Cer. Soc. 2018, 38, 1002-1017. [CrossRef]

12. Binas, V.; Papadaki, D.; Maggos, T.; Katsanaki, A.; Kiriakidis, G. Study of innovative photocatalytic cement based coatings: The effect of supporting materials. Const. Build. Mater. 2018, 168, 923-930. [CrossRef]

13. Peng, F.; Ni, Y.; Zhou, Q.; Kou, J.; Lu, C.; Xu, Z. New g- $\mathrm{C}_{3} \mathrm{~N}_{4}$ based photocatalytic cement with enhanced visible-light photocatalytic activity by constructing muscovite sheet $/ \mathrm{SnO}_{2}$ structures. Const. Build. Mater. 2018, 179, 315-325. [CrossRef]

14. Wang, D.; Hou, P.; Zhang, L.; Xie, N.; Yang, P.; Cheng, X. Photocatalytic activities and chemically-bonded mechanism of $\mathrm{SiO}_{2} @ \mathrm{TiO}_{2}$ nanocomposites coated cement-based materials. Mater. Res. Bull. 2018, 102, 262-268. [CrossRef]

15. Luévano-Hipólito, E.; Torres-Martínez, L.M.; Cantú-Castro, L.V.F. Self-cleaning coatings based on fly ash and bismuth-photocatalysts: $\mathrm{Bi}_{2} \mathrm{O}_{3}, \mathrm{Bi}_{2} \mathrm{O}_{2} \mathrm{CO}_{3}, \mathrm{BiOI}, \mathrm{BiVO}_{4}, \mathrm{BiPO}_{4}$. Constr. Build. Mater. 2019, 220, $206-213$. [CrossRef]

16. Krutsko, E.N.; Musskaya, O.N.; Kulak, A.I.; Krut'ko, V.K. Photocatalytc Activation of Gypsum Cements. Russ. J. Appl. Chem. 2017, 90, 51-57. [CrossRef]

17. Janus, M.; Bubacz, K.; Zatorska, J.; Kusiak-Nejman, E.; Czyżewski, A.; Morawski, A.W. NOx photocatalytic degradation on gypsum plates modified by $\mathrm{TiO}_{2}-\mathrm{N}, \mathrm{C}$ photocatalysts. Pol. J. Chem. Technol. 2015, 17, 8-12. [CrossRef]

18. Janus, M.; Zatorska, J.; Zając, K.; Kusiak-Nejman, E.; Czyżewski, A.; Morawski, A.W. The mechanical and photocatalytic properties of modified gypsum materials. Mater. Sci. Eng. B 2018, 236-237, 1-9. [CrossRef]

19. Zając, K.; Janus, M.; Morawski, A.W. Improved Self-Cleaning Properties of Photocatalytic Gypsum Plaster Enrich with Glass Fiber. Materials 2019, 12, 357. [CrossRef] [PubMed]

20. Rauf, M.A.; Meetani, M.A.; Hisaindee, S. An overview on the photocatalytic degradation of azo dyes in the presence of $\mathrm{TiO}_{2}$ doped with selective transition metals. Desalination 2011, 276, 13-27. [CrossRef]

21. Zając, K.; Janus, M.; Kuźmiński, K.; Morawski, A.W. Preparation of gypsum building materials with photocatalytic properties. A strong emphasis on waste gypsum from flue gas desulfurization. Przemyst Chemiczny 2016, 95, 2222-2226.

22. Ehm, C.; Stephan, D. Site resolved optical detection of photocatalysis on building materials. J. Photochem. Photobiol. A 2018, 366, 97-102. [CrossRef]

(C) 2019 by the authors. Licensee MDPI, Basel, Switzerland. This article is an open access article distributed under the terms and conditions of the Creative Commons Attribution (CC BY) license (http://creativecommons.org/licenses/by/4.0/). 